\title{
Scare-Quoting and Incorporation
}

\author{
Mark McCullagh
}

\begin{abstract}
I explain a mechanism I call "incorporation," that I think is at work in a wide range of cases often put under the heading of "scare-quoting." Incorporation is flagging some words in one's own utterance to indicate that they are to be interpreted as if uttered by some other speaker in some other context, while supplying evidence to one's interpreter enabling them to identify that other speaker and context. This mechanism gives us a way to use others' vocabularies and contexts, thereby extending our expressive capacities on the fly.

Explaining incorporation involves explaining intra-sentential shifts in lexicon and in context. Shifts of the former sort are familiar to linguists under the heading of "code-switching." Shifts of the latter sort have been less explored; accordingly I explain how to modify Kaplan's logic of demonstratives to allow for such shifts.

I compare the incorporation account of scare-quoting with accounts offered by Brandom, Recanati, Geurts and Maier, Benbaji, Predelli, and Shan. Finally I note a possible implication concerning the speech act of assertion: that you can properly assert a content you do not believe, let alone know, because part of it is expressed with words you do not understand.
\end{abstract}

\section{Introduction}

My aim in this paper is to explain a mechanism that I think is at work in a wide range of cases often put under the heading of "scare-quoting." I call it incorporation. ${ }^{1}$ Incorporation is flagging some words in one's own utterance to indicate that they

\footnotetext{
${ }^{1}$ By using this term I do not mean to pick up on what Herbert Clark and Richard Gerrig (1990) mean by "incorporated quotation." By "incorporation" they mean a relation that can obtain between the playing of some bit of music, and the rhythm thereby demonstrated to a listener (789). (That is the instance with which they introduce the notion.) As will become clear, the relation I have in mind is very different. (Clark's and Gerrig's concerns are largely orthogonal to mine, since their
}

M. McCullagh ( $\bowtie)$

University of Guelph, Guelph, Canada

e-mail:mmcculla@uoguelph.ca 
are to be interpreted as if uttered by some other speaker in some other context, while supplying evidence to one's interpreter enabling them to identify that other speaker and context. This mechanism gives us a way to use others' vocabularies and contexts. It can be useful not only for purposes of rhetorical vividness but also in cases where a speaker's vocabulary lacks some words that express a content he wishes to express: it enables him to extend his own expressive capacity on the fly.

I'll start by presenting some examples and remarking on terminology; then I'll explain the mechanism and show how it applies to the examples. Finally I'll contrast this account with others in the literature. Various writers have proposed accounts of the sort of data I discuss but they err, I will argue, in trying to assimilate the cases either to use or to mention. Incorporation is neither of these.

\section{Some Data}

Discussions of "scare quotation" and of "mixed quotation" are vexed by differences over the range of cases those terms cover. I'll discuss the terminological issues after putting my own range of cases on the table, as my main interest is in explaining the one mechanism that is at work, I think, in these cases regardless of what headings different writers would put them under.

I will follow the lead of Stefano Predelli's (2003) discussion of scare quotes, and look into what various style and usage manuals say about certain uses of quotation marks. Predelli cites four usage guides (Perrin and Smith 1968, Kierzek 1977, Chicago 1982, Ehrlich and Murphy 1991); my excuse for looking at a few additional ones is that there are some types of use described in them that aren't described in any of these four. Another interesting point is that in a couple of cases, the changes over different editions suggest an increase in the use of the described uses of quotation marks, or at least a greater acceptance of them.

Here are some uses of quotation marks that the manuals describe and accompany with examples. With the exception of those from Greenbaum (1996) (which are from the International Corpus of English), as far as I know the examples that the manuals give are all unattested. I'll give under each heading one or more actual examples from various sources. I should emphasize that I don't construe these headings as exclusive; several examples fit under multiple headings. But it is impressive how much convergence there is: most of the functions listed are described as legitimate in multiple style manuals.

1. Indicating that the enclosed words are slang (Chicago 1982: 173, Baker 1984: 407, Todd and Hancock 1986: 460, Greenbaum 1996: 548, Birchfield 2004: 646, Chicago 2010: $\$ 7.57$ actually deprecates the use of quotation marks to flank slang expressions, saying they are "rarely needed").

paper almost entirely concerns the speech-act classification of various quotational or quotation-like performances rather than a systematic account of their semantics.) 
Bro Hug In a series of photographs last May, BuzzFeed cruelly broke down President Obama's botched farewell hug to his departing press secretary, Jay Carney, calling it "The Most Awkward Hug in White House History." Mr. Carney's "weird flappy hand" gave way to the president's "Raptor hand," which caused Mr. Carney seemingly to kiss the president's shoulder, after which the president "bro yanked" Mr. Carney's head and gave him a flash of "side eye." (New York Times, September 26, 2014)

2. Indicating that the enclosed words are technical jargon (Birchfield 2004: 646, Stilman 2010: 185 ("enclosing it in quotation marks sends a reassuring signal to your readers that they aren't expected to have prior acquaintance with it"); McCarten 2013: 392, Chicago 1982 says that one use is to flank "technical terms in special senses.") (The (unattested) example Chicago gives is of a technical term used incorrectly, in a sort of metaphorical extension. This is different from the other manuals that describe technical terms being used with their technical meanings, as in the following examples.

Aiviq Between 5:34 a.m. and 11:29 a.m., according to a later computer analysis by Rolls-Royce, the Aiviq's "wire tensile strength overload” alarm went off 38 times. (New York Times, December 30, 2014, describing a mishap on an offshore oil-drilling platform)

Tardigrade The tardigrade, which has a natural life span of about a year, is particularly impressive among the exhibit's "extremeophiles." (New York Times, September 8, 2015)

Chassis At a cabinet meeting led by Vice President Joe Biden, [Energy Secretary] Chu unveiled thirteen electrofuels grants. A Boston firm planned to engineer E. coli into "a chassis for iso-octane." A University of South Carolina team would study "electroalcoholgenesisbioelectrochemical reduction of $\mathrm{CO}_{2}$ " (Grunwald 2012: 5)

Bugs We discovered "bugs in the back end" of live updates. (Twitter post from a public relations officer, explaining website malfunction. https://twitter.com/ femwriter/status/562586794815156224)

3. Indicating that the writer somehow rejects the use of the enclosed words (Todd and Hancock 1986: 460 ("Quotation marks may also be used for a word that a writer disagrees with"), Greenbaum 1996: 548 ("the author does not accept responsibility for the wording”), Chicago 2010: $\$ 7.55$ ("Nicknamed scare quotes, they imply, 'This is not my term' or 'This is not how the term is usually applied"), Stilman 2010: 187, McCarten 2013: 392 ("Put quotation marks around words used ironically")).

Good Old Days In the "good old days" our great-great-grandmothers walked several miles to the village. (Greenbaum 1996: 548)

Chomsky The hideous slave labor camps of the new "empire of liberty" were a primary source for the wealth and privilege of American society, as well as England and the continent. (Noam Chomsky in New York Times, March 18, 2015) 
Lizard As 12 million Americans "know," the United States government is run by lizard people. (The Atlantic, October 31, 2013)

Krugman [R]ight-wing think tanks are still cranking out "studies" purporting to show that health reform is a failure. (Paul Krugman in New York Times, August 10, 2015)

Murderer Cross dressing "murderer" moves into Harlem townhouse (New York Post headline, October 24, 2011)

4. Indicating that the enclosed words are someone else's choice (McCarten 2013: 392 ("Use quotation marks to set off a pungent or significant word or phrase... justifiable only when the words are controversial, add colour or give the flavour of an event or the style of a speaker")).

Denikin After Denikin triumphantly entered Tsaritsyn and attended services in its Orthodox cathedral, on July 3, he "ordered our armed forces to advance on Moscow." (Kotkin 2014: 326)

Bush After a run through of "ideas I strongly reject," Bush finally got around to announcing that he was going to "talk about what we're for." (New York Times, March 15, 2008)

Lenin Lenin did speak at the Fourth Comintern Congress, for an hour, in German, but he was drenched in perspiration and told people that during the speech he had "forgot what he had already said, and what he still had to say." (Kotkin 2014: 418)

5. Indicating that the enclosed words are from some common background, e.g. a cliché or a canonical text (Chicago 1982 endorses this use but the 2010 edition deprecates it).

Axe While the initial news of remission is often met with relief, many patients realize quickly that the good news comes with some grave caveats as they "wait for the axe to fall." (New York Times, September 10, 2015)

Militia Another fine day for America's "well regulated militia". (John Gruber's blog, after a mass shooting in the U.S. http://daringfireball.net/linked/2015/ 08/26/virginia-tv-shooting)

6. Indicating that the enclosed words are someone else's (Gibaldi 1998: 77 ("Place quotation marks around a word or phrase given in someone else's sense or in a special sense or purposefully misused"), Chicago 1982: 173 (indicating that the expression they enclose is "foreign to the normal vocabulary of the speaker"), Swan 2005: 240 ("[in headlines,] Quotation marks ... are used to show that words were said by somebody else, and that the report does not necessarily claim that they are true")).

I don't give examples under this last functional heading because I believe that it covers all of the examples given under previous headings. Indeed, my proposal builds on this core idea. My suggestion will be that in all the examples I gave there is one semantic mechanism at work. The multiplicity of uses listed in the manuals is 
simply due to the fact that there are different reasons that writers can have for using that one mechanism, and different suggestions they thereby make to their audience in different cases. The mechanism, of course, is incorporation.

\subsection{Terminological Digression}

I think that the term "scare quoting" does a decent job covering the phenomenon in question. I say this with some trepidation since I doubt that that term (or the term "shudder quotes") has an agreed meaning even among philosophers and linguists; probably any use of it to demarcate some field of data, even preliminarily, will be contestable. (As Paul Saka (2013) notes, the literature on quotation has been bedeviled by the difficulty of demarcating different subfields of data.) I have found that some colleagues, perhaps leaning on the word "scare," take it to be a necessary condition that there is some criticism, perhaps only implicit, of the words flanked by quotation marks (or dancing fingers). Others don't; they would include under the heading many cases in which nothing like that is being indicated. (When I've asked those people in the former group what label they'd apply in these cases, they've been at a loss.) To some, perhaps, the term is just a catch-all for uses of quotation marks that are evidently not of one of the kinds long recognized by philosophers and linguists.

There is also the phenomenon now known as mixed quotation, which I mention without taking a stand here on whether it really is a distinct phenomenon from scare-quoting. As far as I know this terminology is due to Herman Cappelen and Ernie Lepore (1997) who wrote, "The category of mixed quotation is more or less ignored in the literature" (429n.1), although they do credit Davidson (1979: 81) for acknowledging it. The working example they use is

Alice said that life "is difficult to understand"

in which we have a reporting verb ("said") and a "that"-clause as its complement, part of which is flanked by quote marks.

Davidson did write of a "mix of use and mention" (not "mixed quotation") in his 1979 paper, but it's unclear whether by that he means what Cappelen and Lepore mean by "mixed quotation," since Davidson included as examples cases in which no speech act is being reported, e.g.

Dhaulagiri is adjacent to Anapurna, the mountain whose conquest Maurice Herzog described in his book of the same name. (81)

(I'm not sure that any of the theories I'll discuss below would apply to examples like this.) For Cappelen and Lepore, on the other hand, it is essential to "mixed quotation" that a speech act is being reported:

a basic fact about mixed quotation... [is that it] contains a component that serves two functions concurrently. The quoted part is both employed to report what the speaker said and it is employed to say, at least partially, what the speaker actually uttered. (436) 
Furthermore they take it that every mixed quotation stands in some entailment relation with an indirect quotation (1997: 430). What this suggests is that by "mixed quotation" they, at least, mean a mix of direct and indirect quotation rather than the sort of mix - of use and mention - that Davidson described. ${ }^{2}$

It may be the case that the right thing to say about scare quotation is also the right thing to say about mixed quotation. I won't take up that question in this paper. But I will register commitment to a conditional claim: that if mixed quotations are partly about words - that is, if there is a term in their proper parsing whose semantic value is the same as that of some pure quotation - then it is a different phenomenon from scare-quoting. The reason I say this is that on the account I'll propose, scarequotings are not about words (in the sense just described). So for me, the possibility of an equivalence comes down to the question of whether the mixed quotation about Alice says or merely suggests that she uttered "is difficult to understand" (in the course of making the reported statement). ${ }^{3}$ And evaluating that claim would be too large a digression from the present topic. (For discussion see Recanati 2001: 65961; Cappelen and Lepore 2005: 66; Recanati 2010: 290-302; De Brabanter 2013: 130-32.)

So ends my terminological digression.

It's likely that scare-quoting is becoming more common. The first edition of Fowler's guide (1926) makes no mention of the practice that the 3rd edition (2004) blandly describes: "Quotation marks may be used to enclose slang and technical terms" (646). And the 13th edition of the Chicago Manual of Style (1982) doesn't even use the term "scare quotes" while the 16th edition (2010) uses it to head an entire section on their use. Perhaps with the increased access that the World Wide

\footnotetext{
${ }^{2}$ On this terminological point there is variance even among some authors I discuss below. For example, Geurts and Maier (2005: 109) and Shan (2010: 418) clearly mean the latter while in addition to Cappelen and Lepore, Recanati (2010: 215) clearly means the former. In line with this conception, I will take it that a necessary condition for being mixed quotation is that a reporting verb is being applied to a "that"-clause, part of which is quotation-mark-flanked. (This is a terminological stipulation I'm making just for clarity's sake. The following case seems evidently a reporting use of a quoted phrase even though there is neither a reporting verb nor a "that"-clause:

After [Ian Fleming's] first heart attack in 1961, he wrote to Christopher Soames, Britain's minister of agriculture, hoping to determine "the finest liquor obtainable in England," now that he was condemned to a mere three ounces a day. (New York Times, November 24, 2015)

Other such examples are given in De Brabanter (2005: 5).) I think it is clearly not a sufficient condition, since if there is such a thing as scare-quoting then - as Cappelen and Lepore note (2005: 73n.7) - there should not be any barrier to its being done in part of a "that"-clause complement to a reporting verb, in which case the resulting sentence does fit the description just given. (One of the examples I presented, Lenin, illustrates exactly this point.)

${ }^{3}$ The parenthetical qualification is important and easy to neglect: as Geurts and Maier (2005) (discussed below) point out, Potts's (2007) account of mixed quotation fails on this score inasmuch as it understands mixed quotations as mere conjunctions of direct and indirect. (Gomez-Torrente (2017:135) gets the relation right, offering an account on which one of the conventional uses of quotation marks is to "add an adverbial or prepositional indication" rather than a conjunct.)
} 
Web gives us to different jargons and vocabularies, scare-quoting has more use nowadays than before.

In addition to showing the variety of uses writers make of scare-quoting there are two broader points that even a brief survey such as this makes. One is that we interpret scare quotes very easily, even when they involve indexicals-I doubt that anyone reading any of the examples was brought up short. (Indeed it's possible to misinterpret Lenin as a case of mixed quotation-but I doubt that anyone did that!)

Another is that scare-quoting is a very common device among educated writers. This distinguishes it from free indirect discourse, which is used primarily in literary texts (discussed by Johnson 2017), and from the much-mocked uses of quotation marks to indicate emphasis (Keeley 2010, discussed in Gomez-Torrente 2017, this volume). Scare-quoting is part of most contemporary writers' toolkits. Despite what I'll argue is some non-trivial machinery under the hood, we take scare-quoting in stride. We should want our account of it to reflect this. The account I'll offer does not involve crediting speakers or interpreters with any special concepts that they need to bring to bear on utterances involving scare-quotes.

\section{What Incorporation Is}

I said that incorporation occurs when one speaks while indicating, of some words in one's sentence, that they are to be interpreted as if used by another. This affects how an interpreter is to carry out two tasks.

Any interpreter, of any utterance, must assign meanings to its constituent expressions. She must also select some context in relation to which she interprets any of the utterances' context-sensitive expressions. In the typical case the interpreter works with a lexicon that they believe states the meanings those expressions have in the speaker's idiolect. Performing the first task, then, is selecting entries from this lexicon. Also in the typical case, it is obvious who the speaker is, when they speak, and where. Performing the second task, then, is choosing these values for the parameters used in evaluating whatever context-sensitive meanings are selected from the lexicon.

Things go differently in cases of incorporation from how they go in the typical case. The two tasks just described must be re-done for the incorporated words. The interpreter has to shift to a different lexicon: one that states the meanings that those words have as used by that other speaker. She must also evaluate relative to a different context: that of the other speaker. And she must shift back, once she has finished interpreting the incorporated words.

Suppose then that a speaker $A$ utters a sentence $S$ in context $c_{A}$ while indicating, of some part of $S$, that it is being incorporated. This means that $A$ is indicating to an interpreter that that part is to be treated as if spoken by another. Suppose also that the evidence available to the interpreter suffices for her to identify speaker $B$ as that other speaker and $c_{B}$ as the context in which items from $B$ 's lexicon are to be taken. 
(Note that $c_{B}$ is not thereby identified as a context in which $B$ utters those words. Whether that's the case makes no difference to the interpretative procedure.)

The interpreter must assign meanings to the words in A's utterance. So in each case she asks: is this word part of the incorporated part, or not? If it is, then the interpreter looks up the word in the lexicon she has for $B$; if it isn't, then the interpreter looks it up in the lexicon that she has for $A$.

The interpreter must also interpret words relative to some context of utterance. In each case she asks: is this word part of the incorporated part, or not? If it is, then she interprets the word relative to context $c_{B}$; if it isn't, then she interprets the word relative to context $c_{A}$.

These two tasks are, in Kaplan's terminology, pre-semantic. "[G]iven an utterance, semantics cannot tell us what expression was uttered or what language it was uttered in. This is a pre-semantic task" (1977: 559). On Kaplan's conception, semantics is the business of calculating, on the basis of whatever initial values (including a parsing of the utterance) are required, a truth value (or condition) for an utterance; pre-semantics is the business of selecting those initial values. ${ }^{4}$

Clearly there is nothing quotational, in the traditional sense, about incorporation: for neither the demarcated words nor the words plus the demarcating marks are interpreted as denoting linguistic expressions (whether types or tokens), or even characters. $^{5}$

Like any mechanism, incorporation can fail. The second supposition that I made in setting up our schematic case is non-trivial: it is possible for $A$ to fail to ensure that the interpreter's evidence does suffice to identify a speaker and context for the incorporated part. This leaves the interpreter unable to interpret that part. But of course the possibility of this sort of failure is not unique to incorporation. It is a possibility that accompanies any use of language. One can hear some words uttered but not know what language they're in; or who is uttering them; or where the speaker is. In such a case one doesn't know enough about the utterance to be justified in selecting any particular lexicon (the first case) or giving any particular values to the contextual parameters (the other cases). Although typically easy, pre-semantics can be difficult, and it can fail.

\footnotetext{
${ }^{4}$ Setting things up in this way reveals a possibility that I think is not acknowledged in Michael Johnson's essay (this volume), where he infers from the claim that quotation marks "don't articulate linguistic items" to the claim that they "are irrelevant for assigning semantic contents to sentences" (289). This inference ignores the role that context plays in determining content: scare-quotes indicate a shift in context and thereby affect content, even if they aren't "linguistic items." In Kaplan's terminology the point is that whatever affects pre-semantics consequently affects semantics, even if it isn't itself semantic.

${ }^{5}$ I say "in the traditional sense" because, as Paul Saka (2013) notes, "there is no consensus on defining quotation" (940). On his own view, for example, the function of quotation is simply to "rule out customary reference as the intended interpretation" of the quoted words (1998: 127). In Saka's terminology my point would be that there is nothing citational about incorporation.
} 
The second supposition also embodies an idealization, since what is more common is that the interpreter will be able to identify a type of person or a type of context. (Several of our examples will be handled in this way.) This is fine if it makes no difference to the resulting interpretation which particular person, or context, of that type is selected.

I will discuss this identification task in the course of treating the examples. In almost all cases it's completely obvious what the scare-quoted speaker/context is, which just goes to illustrate how in successful uses of scare-quotes there is more than enough evidence for the interpreter to succeed in the identification task. But I want to be explicit that the identification task is a separate one from that of determining a truth condition. Undertaking the latter task presupposes success in the former. (Thus on my account it cannot be the case that success in the identification task requires prior success in the calculation of a truth condition.)

\subsection{The Two Shifts That Incorporation Involves}

Notably, each of the two sorts of intra-sentential interpretative shifts that incorporation demands - in lexicon and in context-is already exemplified separately in different phenomena; so they already require explanation, no matter what our view of incorporation or scare-quoting. Intra-sentential lexicon shifts occur in what linguists have investigated under the heading of "code-switching," wherein bilinguals change from one language to another mid-sentence. And intra-sentential context shifts occur in some very simple cases involving indexicals, e.g. a speaker using "here" multiple times in a sentence while changing positions during its utterance. Cases of these two sorts are not cases of incorporation. But the right stories about how they work combine into a story about how incorporation works.

Code-switching is a phenomenon well-studied by linguists (Poplack 1980; Poplack and Sankoff 1984 are two important early articles in this literature.) Bilinguals produce and interpret utterances of this sort with ease. In these cases, of course, the interpreter is not switching from one speaker's lexicon to another speaker's lexicon, since the one speaker speaks both of the two public languages involved. But it's the sort of shift that would be involved in interpreting a nonbilingual who indicated, of some of his words which are not in the public language he speaks, that they were to be interpreted as if spoken by another who does speak

a public language that has entries for those words. From the interpreter's point of view, the shift is of the same kind in both cases: she consults her lexicon for Spanish (say) when interpreting part of the speaker's utterance and that for English when interpreting the rest of it.

The second sort of shift is one the very idea of which requires some elaboration. The basic phenomenon of intra-sentential shift in context is acknowledged, especially in relation to quantifiers (see Stanley and Williamson 1995 and the works cited therein in n. 4.). But there is no generally accepted formal treatment of it. In the next section I will explain one treatment-based on a simple modification of 
David Kaplan's logic of demonstratives - that I think works nicely. Before getting to that I need to explain what I mean by "indicating," when I used that notion in explaining incorporation.

\section{2 "Indicating"}

When I say that the speaker "indicates" some other speaker and context, it's important that by "indicating" I don't mean describing. The indicating I mean is a matter of giving evidence to the interpreter to help her with the two tasks of selecting a lexicon and selecting a context. In the typical case, such evidence is manifest and ample: the interpreter knows who the speaker is - therefore which lexicon to useand where he is, the time of his utterance, and so on-therefore which values to use for the contextual parameters. But even in cases not involving anything like scarequoting, there are ways to indicate that the latter should be changed mid-sentence.

Probably the simplest example concerns the location contextual parameter. There is a very simple way in which a speaker can often indicate that the interpreter should change what value she assigns that parameter. It is simply to change his location. The speaker doesn't say that he's changing location; nor does he describe another location; nor is there a "change parameter value" node in the parsing of the sentence. He just changes location; doing so gives evidence that- "indicates" that-his location has changed.

I said "often" because a change in the speaker's position doesn't always call for a change in the value of the parameter with respect to which an interpreter evaluates position-sensitive expressions. One sometimes moves while one speaks, and time always passes no matter how quickly one speaks, but in most cases this is irrelevant to interpretation. In such cases there's no harm in an interpreter's leaving unchanged the values she assigns to the contextual parameters even though there are changes in the real-utterance features they are meant to reflect. Thus there is nothing surprising in the fact that the leading theory of context-dependence, Kaplan's, works with sentence-context pairs, the idea being that the entire sentence is evaluated when taken in one context. But in other cases such changes are highly relevant and matter to truth conditions. Suppose that a speaker changes position-from near the fireplace to near the window-while uttering the following sentence:

Two Heres It's warm here, but here it's quite a bit cooler.

In such a case each occurrence of "here" is to be interpreted as denoting a different place. (Prima facie, such cases challenge the Kaplan approach; I'll discuss this issue below.)

Another type of example is of what Ruth Kempson et al. call "shared utterances," in which one speaker completes an utterance begun by another (Kempson et al. 2001; Purver and Kempson 2004). In some such cases we will have two occurrences of "I" within one (shared) utterance, that evidently denote different people. Thus the situation evidently demands of an interpreter that she change the value for 
the speaker parameter mid-way through her interpretation of the shared utterance. Neither speaker said that the change is required, but the overall situation evidently indicates it.

The indicating that incorporation involves is of the same general sort as in Two Heres or in shared utterances. What incorporation requires is that the speaker somehow indicate that a mid-utterance re-doing of two crucial pre-semantic tasks is called for, and indicate also how the re-doing should be done: whose lexicon should be used, and which context should be used in evaluating the indicated part of the sentence. Success in incorporation requires that the interpreter have enough evidence to do as the speaker intends. The evidence available to the interpreter-the presence of which is part of what I am counting as the speaker's "indicating"should suffice to identify the relevant other speaker and context. The evidence could be background knowledge, knowledge about what has happened already in the conversation, or knowledge about the statement itself.

\section{Intrasentential Change in Context}

I said that the very idea of intra-sentential shift in context requires some defence; in this section I supply that defence, by explaining how to implement such shifts in a simple semantic system and by meeting objections to the very idea of such shifts. Since David Kaplan's $(1977,1989)$ work on demonstratives is a touchstone, I will work within his logic of demonstratives (henceforth, LD). I'll explain how intra-sentential changes in context might be implemented by modifications to LD.

\subsection{Modifying LD}

In the definition of truth in LD that Kaplan gives, truth is assigned to the language's well-formed expressions "in" structures, "when taken in" contexts, "under" assignments of values to variables, and "with respect to" times and worlds $(1977,544)$. So in a case of a given calculation in that system, the pre-semantic tasks are to decide on a structure, a context, a variable assignment (irrelevant except for open sentences), a time and a world. With world and time left unspecified, what we get is a truth condition rather than a truth value.

What intra-sentential context shifts could we handle in a modification of that language? One might think that we would have to require that only well-formed expressions can be context-shifted. Under that restriction, we could have

$$
F a b \vee " G c d "
$$

as a permissible case (where quotation marks flank the part to be interpreted in a different context) but not 
$F a b \vee G$ "cd"

since the latter marks only a sequence of term expressions, which isn't itself a wellformed expression. But in fact we won't need any such restriction; context-shifting of non-constituents (in this sense) is not a problem. We can introduce the approach by considering one of the simplest clauses in the definition of truth in LD, the one for conjunction. Here is what Kaplan gives ${ }^{6}$ :

$$
4(i) \models_{c w}(\phi \wedge \psi) \text { iff } \models_{c w} \phi \text { and } \models_{c w} \psi
$$

In English: a conjunction is true at a 〈context, world $\rangle$ iff each of its conjuncts is true at that $\langle$ context, world $\rangle$. Here is what we write instead, in order to accommodate the possibility of one conjunct being taken in a different context from the other:

$$
4(i)^{*} \models\left\langle c_{1}, c_{2}\right\rangle_{w}(\phi \wedge \psi) \text { iff } \models_{c_{1} w} \phi \text { and } \models_{c_{2} w} \psi
$$

In English: a conjunction is true at a $\left\langle\left\langle\right.\right.$ context $_{1}$, context $\left._{2}\right\rangle$, world $\rangle$ iff its first conjunct is true at $\left\langle\right.$ context $_{1}$, world $\rangle$ and its second is true at $\left\langle\right.$ context $_{2}$, world $\rangle$.

The change to Kaplan's scheme that we are introducing is that contexts can be complex. Let $C$ be the set of contexts in Kaplan's system LD. Let $C^{*}$ be the closure of $C$ under ordered $n$-tupling. $C^{*}$ comprises anything that can be built by ordered $n$-tupling out of the raw materials: the original-henceforth simple-LD contexts.

Consider now the clause for atomic sentences. In LD it is:

$$
\text { 2. } \models_{c w} \pi \alpha_{1} \ldots \alpha_{n} \text { iff }\left\langle\left|\alpha_{1}\right|_{c w} \ldots|\alpha|_{c w}\right\rangle \in I_{\pi}(\omega)
$$

We modify this to allow each term to be taken in its own context. (We preserve the idiosyncratic feature of Kaplan's system, that no predicate letter can be contextsensitive.)

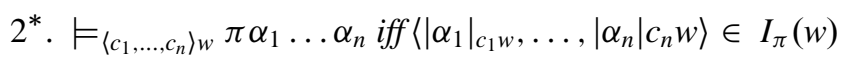

Other clauses are handled similarly; call the resulting system LD*. ${ }^{7}$ Let's illustrate now, using the example I mentioned earlier:

$$
F a b \vee G \text { "cd" }
$$

\footnotetext{
${ }^{6}$ I simplify notation somewhat. Where Kaplan has subscripts for context, variable assignment, time and world, I have one for context and one for world. I also use $\alpha_{n}$ schematic variables for terms, glossing over Kaplan's distinction between "position terms" and "individual terms" (542).

${ }^{7}$ Full details are in another paper that I am preparing for publication. This approach to handling intra-sentential changes in context is significantly different from that proposed by David Braun (1996) and from the more recent proposal of Geoff Georgi (2015). But this is not the place to get into such details.
} 
For this sentence we need a context whose structure is $\left\langle\left\langle_{-},\right\rangle_{-},\left\langle_{-},\right\rangle\right\rangle$, since (as mentioned above) there is no context-sensitivity of predicate letters in LD. Since the arguments to $G$ are marked for context-shifting, and no other shifting is indicated, we will have something like $\left\langle\left\langle c_{1}, c_{1}\right\rangle,\left\langle c_{2}, c_{2}\right\rangle\right\rangle$ where $c_{1} \neq c_{2}$. "Fab" comes out true (at some world-time pair) if " $a$ " and " $b$," when each taken in context $c_{1}$, have values (at that same pair) that are in the extension of the interpretation of " $F$." Similarly for " $G$ ' $c d$ " except that the two terms are interpreted when each is taken in context $c_{2}$. So even though the part marked for context-shifting- " $c d$ "-isn't itself a well formed expression, the evaluation goes through.

\subsection{Too un-Kaplanian?}

One might wonder whether we have gone to the other extreme from Kaplan. In his LD each well-formed expression is evaluated relative to one simple context. In our modified system there is no upper bound to the complexity of contexts. This is necessary for the system to work, since there is no upper bound to the complexity of well-formed expressions in LD, and complexity in the latter demands the same in the former, if a calculation is to be made. Perhaps all this seems unduly complicated.

Although this is not the place for a full investigation, there are two comments worth making. First, it is easy to model the cases in Kaplan's system as special cases of those handled in the modified system. For typically we will want all of the simple contexts involved in the evaluation of an expression to be the same simple context. In that case the complexity is otiose: the evaluation according to the modified rules gives the same result as that according to the rules of LD. That is, if $c$ is the only simple context out of which the complex context $c^{*}$ is built, then each simple component of an expression taken at $c^{*}$ will itself be taken at $c$, which is the same as what happens by design in Kaplan's system when $c$ is the one context in which the whole expression is taken. Second, it must be acknowledged that there is one new implication of working with complex contexts. In LD, every context is suitable for the evaluation of every well-formed expression. This is not the case in the modified system. For example, the complex context $\left\langle c_{1}, c_{2}\right\rangle$ is unsuitable for the evaluation of a simple expression such as "I" or "today." (This is so regardless of whether $c_{1}$ or $c_{2}$ is itself complex.) Aside from the mismatch in complexity there is another problem. For "I" requires that the context supply a time. Now, even if each of $c_{1}$ and $c_{2}$ supplies a time, which time would an ordered pairing of them supply? Although it may be possible to define some notion of the time of a complex context, it seems better just to require that simple expressions be evaluated when taken in simple contexts. Here is how we do this in the modified system. Consider the clause for "I" that Kaplan has:

$$
\text { 12. }|\mathrm{I}|_{c w}=c_{A}
$$


We reflect the unsuitability of $\left\langle c_{1}, c_{2}\right\rangle$ for evaluating "I" by putting the following clause into our modified system.

$$
12^{*} \text {. If } c \in C \text {, then: }|\mathrm{I}|_{c w}=c_{A}
$$

That is, the value of "I" is defined only when it is being taken in a simple context. So working with complex contexts means giving up on one feature of Kaplan's LD: that every context is suitable for the interpretation of every expression. But it seems a small cost, and I cannot see that there is any great truth about language or interpretation that entails that every expression can be evaluated when taken in every context. What we might want to endorse is a much weaker principle, that every expression can be evaluated when taken in any context in which it is uttered. (It's worth noting that $\mathrm{LD}^{*}$ does preserve the following principle: that every simple context is suitable for the evaluation of every simple expression in the language. I note this just to point out that it's there for those who like that sort of feature of Kaplan's system, not because I think that preservation of this particular principle is a criterion of adequacy for a semantic treatment of context-sensitivity.)

The application of this modified system to Two Heres and the like is obvious: each "here" is taken in its own simple context, each of which supplies a position value that slightly differs from that of the context used in the evaluation of the next occurrence of "here." Thus we get the intuitively correct truth condition for the utterance, which Kaplan's original system cannot give. Similarly for analogous cases involving multiple occurrences of "now."

And at this point we notice an interesting thing, which makes possible incorporation in all its aspects. For although we introduced the need for a revision to Kaplan's system with a very ordinary example (Two Heres), in fact the revised system is ready to handle cases that are much less ordinary: cases in which the contextual feature that requires shifting is the speaker. As far as formal semantics is concerned, the speaker parameter is simply one more parameter, completely on a par with the time and location parameters. But while everyone would agree that shifts in location or time, during the course of an utterance, often occur and are sometimes semantically relevant, many will be less ready to agree that it's even possible, let alone semantically relevant, for a change in speaker to occur during the course of an utterance.

But in the shared utterances cases mentioned above we already have instances in which the speaker does change during the course of the utterance. They're not cases of incorporation, as I have defined it, since there is no one speaker of the overall sentence. But they are cases in which the interpreter should, in interpreting first person indexicals, change part-way through their interpretation of the sentence the value that they assign to the speaker parameter.

Cases of incorporation are handled in exactly the same way. Where they differ from the shared utterance cases is that rather than the speaker actually changing, the speaker indicates that an interpreter is to treat part of the sentence as if it were produced by a different (indicated) speaker. This indicating is, again, something that 
matters to the pre-semantics, not something that changes how the calculation goes once the initial values are supplied to it.

\section{Intrasentential Shift in Lexicon}

I've dwelt just now on the nature of one of the two interpretative shifts called for by incorporation. What about the other shift, a shift in lexicon? This is much less problematic a notion than intra-sentential context shift. In the Kaplanian setting, a "shift" in lexicon is a shift to a different set of character-specifying lexical axioms in the formal system.

Suppose that (in our schematic case) $A$ scare-quotes some word, indicating that it is to be treated as if used by $B$, and that the word does exist in both $A$ 's and $B$ 's lexicons but with different meanings. Then the formal system will have two axioms for that word, one stating the character it has when used by $A$, the other the one it has when used by $B$. "Shifting" to $B$ 's lexicon just means, in such a case, using the latter axiom rather than the former in a calculation of the utterance's truth condition.

The word "shift" is slightly misleading as a word for the general case, since we also include cases in which the scare-quoted expression has no meaning when used by $A$ : it is not in $A$ 's lexicon. Formally the upshot is the same: the axiom for its meaning when used by the indicated speaker, $B$, is used in the calculation. Since there is no axiom giving its meaning as used by $A$, there is nothing shifted from. But this small misleading implication is not problematic in itself-the account still works in these cases, a calculation can be done-and it is nice to have one term, "shift," to cover what is happening both to lexicon and context. So I will continue to use it.

\section{Applying the Account}

With accounts of intra-sentential context- and lexicon-shifting in hand, we are ready to apply the incorporation account to our examples. I'll select a few that (in my judgment) bring out challenging or interesting features of the account.

\subsection{Chomsky}

In this example the phrase "empire of liberty" is scare-quoted. Had the sentence occurred just on its own, a reader wouldn't know enough to identify a particular speaker (or type of speaker) as the other-the $B$, in our schematic treatment at the start of $\$ 3$ - whose use is being indicated; the identification task would fail. But the topic of the larger discourse is the early United States. So an interpreter 
has evidence that the other (whose context and lexicon are being recruited in his sentence) is someone whose lexical entries are such that the early United States is in the extension of the phrase "empire of liberty." Interpreting the phrase this way gives the correct truth condition for the sentence as a whole - again, since it is the early United States that Chomsky is discussing.

Obviously there is more going on in Chomsky's scare-quoting than just that it is being used to get his sentence to have a certain truth condition. (He could, after all, have achieved that just by using the phrase "the early United States" normally.) The reader obviously is meant to infer from Chomsky's highlighting its reliance on slave labour, that he would not include the early United States in the extension of the phrase "empire of liberty." But there are two important points to make about this fact.

First, it is not a fact that bears on the utterance's truth condition. For interpreting the phrase according to Chomsky's meaning gives the wrong truth condition. On that interpretation his utterance cannot be about the sources of wealth of the early United States-which is, again, evidently what he is discussing. For the semantic task-that of ascertaining the utterance's truth condition-it is only the other's lexical entries (and context) that matter.

Second: in doing the identification task an interpreter doesn't need any information about how "empire of liberty" stands in Chomsky's lexicon, let alone that he wouldn't use it to characterize the early US. All an interpreter needs is the evidence (in previous sentences) that the topic is the early US. That is enough to carry out the identification task: it is evidence that the other speaker's lexicon is such that the early US is in the extension of "empire of liberty.""

We can illustrate these points by varying the case. Suppose the sentence had been:

The lush fields and forests of the new "empire of liberty" were a primary source for the wealth and privilege of American society ...

Then there wouldn't be the same implication of rejection, i.e. of the writer's not counting the early US as an "empire of liberty." For in this variant case it's possible that the scare-quoting was being done just to indicate that the writer acknowledges the provenance of that phrase in some other source. But as in the original case, an interpreter does have enough information to know that the other whose lexicon and context are being deployed does include the early US as an "empire of liberty"-for in this variant case too, that is evidently the topic of the discussion. The identification task doesn't rest on that of figuring out how the word stands in the writer's lexicon.

\footnotetext{
${ }^{8}$ In fact it was a phrase that Thomas Jefferson used in 1780 to stand for the "American union" he envisioned as the fruit of the Revolution (Boyd et al. 1950-: 4:237-38). Most of Chomsky's readers, however, would not know this. I'll treat the case as a typical reader would interpret it.

${ }^{9}$ This is clearly a type identification rather than the identification of a particular. And it must be admitted that knowing that the early US is in the extension of "empire of liberty" doesn't suffice to determine one particular lexical entry for "empire" or "liberty." Just as with context it often suffices just to identify a type, so too with lexicon it often suffices to identify a type.
} 


\subsection{Krugman}

In this example only the word "studies" is scare-quoted. The rest of the material in the sentence tells the interpreter to treat it as being used by someone in whose lexicon it applies to products cranked out by right-wing think tanks, purporting to show that health reform is a failure. Presumably someone affiliated with one of these think tanks fits the bill. Interpreting "studies" in this way gets us to the correct truth condition for the utterance.

As with Chomsky, it takes another inference for an interpreter to get to a conclusion about how "studies" stands in Krugman's lexicon. Since the word isn't a technical term, nor is it a poetically impressive construction by some other speaker, it is difficult to see any point to the author's scare-quoting it except to indicate that unlike the right-wing think-tankers he does not include the documents they produce in the extension of "studies."

\subsection{Buzzfeed}

Here we have many scare-quoted expressions. Let's focus on the sentence

The president "bro yanked" Mr. Carney's head and gave him a flash of "side eye."

The intended reader knows that these are not part of the lexicon that a New York Times writer would use in an article. The only other speaker relevant in the context in which this sentence occurs is the Buzzfeed writer. That person is our B. Accordingly the interpreter looks into the lexical entries for that person in order to interpret the scare-quoted expressions.

It may be the case that the interpreter doesn't have such entries at her disposal: doesn't know what the Buzzfeed writer means by the scare-quoted phrases. In that case the sentence is not fully interpretable by her; it is as if she is dealing with a word used normally, whose lexical entry she doesn't know.

One might note that a fallback interpretation is available: that the president did what the Buzzfeed writer calls "bro yanking” to Mr. Carney's head and gave him a flash of what the Buzzfeed writer calls "side eye." Although in many cases such a fallback quotational interpretation is available, we will see below that there are reasons not to work with this idea in accounting for scare-quoting. (The main problems are that (i) such approaches become overly complex when generalizedas they certainly need to be-beyond syntactic constituents such as noun or verb phrases, and (ii) the relations and relata these approaches introduce into the analysis should be available for anaphoric uptake later on, which doesn't appear to be the case in general.) For now, it's worth emphasizing that there's nothing particularly illuminating about the availability of a fallback quotational interpretation. Such an interpretation is also available when unfamiliar terms are used normally. (Imagine someone saying to you, "I only bro-yank immediate family members." If you don't 
know what "bro-yank" means, you still have the fallback interpretation: he said that he does what he calls "bro-yanking" only to immediate family members.) So the availability of a quotational fallback interpretation in cases of scare-quoting tells us nothing about scare-quoting in particular.

What about further inferences, concerning the author's relation to the scarequoted words? Given the conventions of newspaper writing, the most that the interpreter can infer is that the writer knows that it's not permissible to use these terms straightforwardly. She cannot infer that the writer doesn't have them in his lexicon; perhaps he does. (Nor can she infer that the writer has them in his lexicon but with different meanings specified from those of the Buzzfeed writer.) But again: none of this matters to the truth condition of the statement. With the Buzzfeed writer's lexical entries used, we get the correct truth condition for the overall statement.

\subsection{Chassis}

This case is similar to Buzzfeed except that rather than being slang, the scare-quoted expression is a scientific term. Let's focus on the sentence

A Boston firm planned to engineer E. coli into "a chassis for iso-octane."

The writer here indicates to us to look in someone else's lexicon for a meaning of the mark-flanked phrase. Who then is our $B$ ? The reader imagines the author of the proposal-some employee of the Boston firm — as the person whose lexicon should be used in the calculation of a truth condition for the overall sentence.

\subsection{Denikin}

This example differs in several ways from those so far considered. For one thing, there is no hint of a difference in lexical meanings assigned to some word by the writer and the other, nor any suggestion that the (perfectly ordinary) words aren't in the writer's lexicon. (Stephen Kotkin is a professor of history at Princeton University and the selection is from his recent biography of Stalin.) Rather what we seem to have is a case in which the writer thought that the other's phrasing was for some reason worth preserving. Perhaps he thought it somehow evokes the situation. So he inserted that phrase- - "ordered our armed forces to advance on Moscow"-into the sentence, flanking it with scare-quotes primarily to indicate that the phrasing is not his.

The second major difference introduces the other component of our account. For there is an indexical term- "our"-in the scare-quoted part of the sentence. The "our" refers to Denikin's people, not to any plurality involving Professor Kotkin. The account smoothly handles this, as does the reader, who changes the context 
in relation to which she evaluates the expressions in the sentence. For the scarequoted part, she takes it to be a context in which the speaker is some member of that plurality. Although we are likely to think that it is Denikin himself whose words are scare-quoted, it could just as easily be a member of his forces who later wrote a memoir that Professor Kotkin consulted.

Finally there is the fact that the scare-quoted words are English rather than Russian. Let's assume that nobody present on the indicated occasion spoke English. Then none of those people can be the indicated speaker. Is this a problem for the account?

No; on the contrary we see its versatility brought out. For (as was noted above) just as one can incorporate an utterance by $B$ in context $c_{B}$ even if $B$ did not actually utter anything in context $c_{B}$, one can also incorporate an utterance by a non-actual $B$. All that the mechanism requires - all that the semantic calculation requires-is that there be some lexicon and some context to work with (for the scare-quoted part). Whether the lexicon is that of some actual speaker is irrelevant, as is whether the context is one in which the scare-quoted words are being uttered. Thus in a case like Denikin the natural thing to say is that the interpreter is being asked to imagine some English speaker — an English-speaking Denikin, if you like - and to use lexical entries stating the meanings that the scare-quoted words have for that speaker.

\subsection{Lenin}

This example introduces yet another twist. By a grammatical criterion it could count as mixed quotation, since it satisfies our (stipulative) necessary condition: the quotemark-flanked part is within the "that"-clause complement of a reporting verb $(\$ 2.1)$. But if we treat it that way, and our treatment of mixed quotation is one on which the quote-mark-flanked words are necessarily uttered by the reportee, we will fail to give the right results for this example, for Lenin did not, of course, use the word "he" (or the corresponding word in German) to refer to himself. For my part, when reading this sentence I processed it too smoothly, for that oddity didn't even register at first.

Despite the availability of a mixed-quotational construal, however, the reader seamlessly processes it not as a reporting use of the quotation-marked words but as a scare-quoting use, from some source-in this case, an account of Lenin's speech by someone else. That is the person-not Lenin, not Professor Kotkin-whose context matters in the interpretation.

\subsection{Range of the Account}

We have, then, quite a range of cases of scare-quoting whose truth conditions admit of explanation in terms of incorporation. 
Before moving on to comparing the incorporation account of such cases with other accounts, I should note that there are some cases superficially similar to the ones I've discussed, which don't obviously lend themselves to treatment in terms of incorporation. (These cases were brought to my attention by Jonathan Wright in personal communication, for which I'm grateful.) Recall Chomsky and consider:

That [1] "empire of liberty" was not an [2] "empire," and it if had been it wouldn't have been one [3] "of liberty."

(I've numbered the scare-quoted fragments for ease of reference.) The worry is this. No matter whose lexicon we use for all of [1]-[3], we get something selfcontradictory. But the sentence doesn't read as self-contradictory.

One plausible thing to say about this sort of case rests on the fact that the incorporation account does not at all require that every scare-quoted part of a sentence be interpreted using the same speaker-context pair. One could say that for [1] it is Thomas Jefferson being scare-quoted while [2] and [3] are scare-quotations of the speaker, which while semantically pointless have the rhetorical effect of emphasizing that the words are those of the speaker.

Whether that response succeeds is a topic for another occasion; perhaps cases of this sort fall under the heading of metalinguistic negation (see Horn 1985 and the ensuing literature). Whether the incorporation account of scare-quoting extends to an account of metalinguistic negation is also a topic for another occasion.

My claim is that there is a significant range of cases best understood as cases of incorporation. Congruently with the point noted above about terminological unclarity, I do not claim that there is a ready label for exactly the range of cases to which this account so applies. I turn now to a comparison of the incorporation account of such cases with other accounts that have been offered.

\section{Comparison with Other Accounts}

Several linguists and philosophers have undertaken to explain how scare-quoting works. Several of them start from a core idea very much like the one with which I began: that the quotation-mark-flanked words are to be taken as if spoken by some other. But there are different ways of elaborating this idea, and none of the proposals already made relies as mine does on a worked-out account of intra-sentential change of context. Some other accounts start from the idea that scare-quoting makes no difference to the content that a sentence expresses; these accounts founder, I think, on many counterexamples, particularly ones involving indexical expressions.

\section{1 “Semanticizing” Accounts}

One idea is to do what François Recanati has aptly called "semanticizing the contextshift" (2010: 283). On approaches of this sort, what makes it the case that the 
scare-quoted expression is interpreted as if it were uttered by some other, is that the sentence somehow says of that expression, that it is to be interpreted in that way. Recall our schematic scenario: speaker $A$ utters a sentence some part of which, expression $e$, is scare-quoted, and indicates $B$ as the "other" whose lexicon and context are to be used in the interpretation of that part. The idea behind semanticizing approaches is that the presence of the scare-quotes around $e$ effectively replaces it with a different expression, schematically: "what $B$ meant by ' $e$ "' (in which the expression $e$ is purely quoted). We find this idea in several accounts.

- Robert Brandom (1994: 545-47) claims that what is "implicit in" a scare-quoting sentence such as

Those "freedom fighters" butchered the villagers

is made explicit in a sentence that involves a definite description formed in terms of a reference relation whose arguments are a term for some speaker and a pure quotation-in this case,

The ones that he refers to as "freedom fighters" butchered the villagers.

- Recanati pursues an approach of this sort in chapter 17 of his 2000 book, the idea being that "the contextual shift modifies the character of the sentence" (244) Recanati (2000). This phrasing is jarring, since context and character are things that in Kaplan's scheme can't modify each other. But I put this to the side. What matters is how Recanati elaborates this idea. And it is clearly a semanticizing move, as he himself later categorizes it (2010: 283). Consider the example he uses:

Your friend "Quine" is not Quine, he is only McPherson.

In this scare-quoting, the effect of what Recanati calls the "context shift" is to change the character of the word "Quine" into that of the phrase "person named 'Quine' by the addressee" (246). This character is "metalinguistic" (247). Recanati writes:

In general, a context-shifting function $d$ maps a character $c h$ [in the example, the character of the name "Quine"]... onto a distinct character $c h^{*}$ [that of the phrase "person named 'Quine' by the addressee"] such that, for any context $k$ in its domain, $c h *(k)=\operatorname{ch}\left(k^{\prime}\right)$, where $k^{\prime}$ is a context obtained by shifting some aspect of the original context $k$. Thus $d$ shifts the context from $k$ to $k^{\prime}$. (246)

Although Recanati chooses to say that this character-shift "shifts the context," we might prefer to say that by shifting the character, $d$ secures the effect of a shift in context rather than that it somehow shifts the context, since in this account there is nothing that actually does that. Surprisingly (given his repeated use of the phrase "context shift") Recanati himself is actually explicit about this, for he 
frames his proposal as one that sticks with "the standard notion of the character of a complete sentence as a function from (single) contexts to propositions" (243). ${ }^{10}$

We don't find in Recanati's discussion any argument in support of his choice to stick with Kaplan's original one-sentence/one-context framework. As we've seen, the motivation for the idea of evaluating different parts of a sentence in different contexts arises in its purest form in cases that have nothing to do with quotation or "echoic" uses of language: Two Heres and the like. Part of my reasoning towards the treatment of scare-quoting I've proposed is that incorporation is something whose possibility we see before even approaching the topic of scare-quoting; there's no machinery needed specifically for that phenomenon. So if Recanati's reluctance to countenance such a treatment of the scare-quoting cases is based on the idea that it's too high a price to pay in order just to handle "echoic" uses of language, then the reluctance is misguided, for the price already needs to be paid in order to get a theoretically satisfying treatment of certain cases (e.g. Two Heres) involving the plainest sort of context-sensitivity.

- Geurts and Maier (2005) offer an account that they might apply to the cases I'm considering in this paper. On their view, "the semantic effect of quotation is to shift the ordinary meaning of an expression $\alpha$ to a new meaning that involves mentioning $\alpha$ " (119). Applied to Chomsky, for example, this means replacing the scare-quoted phrase "empire of liberty" with " $\left[\begin{array}{l}x \\ e\end{array} Q: E e(x, Q\right.$, empire of liberty)]," meaning: there is an individual $\mathrm{x}$, an event e, and a property $\mathrm{Q}$, such that "e involves x's expressing Q by means of" the words "empire of liberty" (121). That is a semanticizing treatment: we have, in this representation, explicit reference to a phrase and a speaker.

- Yitzhak Benbaji (2004) gives rules for the interpretation of scare-quoting of terms or predicates. The rule for terms is that the scare-quoted term "N" refers to "the thing to which the echoed speaker refers in producing a token that sametokens this. N" (542). Here again the idea is that explicit reference to the other speaker's meaning, and the other speaker's context, does the job of what on the incorporation approach is done by pre-semantic choices.

\footnotetext{
${ }^{10}$ In his 2001 Mind paper Recanati also discusses the same example, offering what seems to be a completely different account of it. There, the case "can be described in terms of a language shift" (674). He goes on to explain that lexical selection is a pre-semantic affair, just as I emphasized above. This proposal is entirely congruent with one component of mine. Whether Recanati sees the 2000 story about context-shift, and the 2001 story about language-shift, as competing accounts is difficult to tell. What complicates the picture even more is that in the 2001 paper there is a different account of context-shifting. This is not a semanticizing account, but one on which "a portion of the utterance is interpreted with respect to a distinct context" (679). Recanati does not elaborate on the idea, nor note what he noted in the 2000 book, that this conflicts with the standard Kaplan approach to the evaluation of sentences when taken in contexts. From the point of view of the incorporation account perhaps Recanati is best viewed as having recognized the need for a theory of simultaneous context- and lexicon-shift, without having explained how the former would work (other than as in the 2001 book: a character-shift that does the work of a genuine context-shift).
} 
Approaches of this sort might seem well motivated by the core idea described above. For reasons I'll soon explain, I think that on reflection they are not at all well motivated by it. For now I note some challenges such views face.

First, on this approach the truth of a sentence involving a scare-quotation requires that the scare-quoted part actually have been uttered by the speaker whose lexicon is being invoked, with some definite reference on that occasion. But this is requiring too much. ${ }^{11}$ Consider Brandom's example. It works as a scare-quote even if the invoked speaker never did utter the phrase "freedom fighters." All that matters is that they are in the phrase's extension, in his lexicon, whether he uttered it or not. (Of course, if "freedom" and "fighters" are in his lexicon then he probably did utter each of those words, on some occasions, with the meanings being invoked by the scarequoting. But it doesn't matter whether he ever uttered them together.) Similarly for "empire of liberty" in Chomsky.

One might propose introducing a modality into the analysis in order to accommodate this point. For example, rather than what $x$ referred to as "freedom fighters" we would have what $x$ could have referred to as "freedom fighters." But this just generates the opposite problem: now the account requires too little. For any expression is one that someone could have used to refer to some particular thing or things-because they could have spoken a language in which that thing is in its extension.

What this suggests, now, is that we build in reference to the speaker's lexicon. So rather than what $x$ referred to as "freedom fighters" we would have what is in the extension of "freedom fighters" in x's lexicon. Now we require notions of lexicon, extension etc. and the more such convolutions we add, the less plausible it is that this is what ordinary speakers mean. (The incorporation approach becomes comparatively simpler, too.)

That points to the second problem, at least from one perspective. For on these accounts one must possess the concepts of quotation and reference (and perhaps extension, lexicon etc.) in order to engage in scare-quoting. And we may wish to be cautious in building into our account of one linguistic practice, the assumption that speakers are proficient with some other, unless there is no other way to explain the former. Since the incorporation account does explain the former (in this case, scare-quoting) without assuming proficiency in the latter (quotation, reference/lexicon specifications, etc.), simplicity considerations favor it over semanticizing treatments.

Third, semanticizing treatments require generalization beyond noun phraseseven beyond constituents, as some writers have emphasized (Abbott 2005; Cumming 2005). To this technical problem there is perhaps a technical solution: perhaps any scare-quoted non-constituent could be seen as the result of scare-quoting some larger constituent and unquoting as necessary, to get to the scare-quoted non-constituent. (See Shan 2010; Maier 2015 on unquotation operations.) On this approach we are presupposing yet another capability in speakers and interpreters:

\footnotetext{
${ }^{11}$ Cf Gomez-Torrente, this volume, p. 135.
} 
proficiency with the unquotation operation. And again, such postulation is something that should weigh in the balance in the overall evaluation of the theory.

Finally there is what in my view is the most serious problem these accounts have. On these accounts there is a hidden (in Brandom's terminology, "implicit") reference to the invoked speaker and reference to the scare-quoted expression. And I think if these references are there, hidden or not, then it should be possible for them to be linked to anaphorically later in the discourse. But this often seems not to be the case with sentences involving scare-quotation, even though it is the case with their semanticized counterparts.

The point I'm invoking here was made quite nicely by Gabriel Segal (1990). It is that if there is genuine reference to something in a sentence, even implicitly, then it is available to be picked up anaphorically: "it is possible to test whether or not a sentence has implicit semantically significant elements by seeing what kinds of subsequent linguistic events make sense after the sentence has been uttered" (105). Davidson's (1963) account of action sentences passes this test, Segal argues, for although there isn't explicit reference to events in "Shem kicked Shaun," the hidden reference can be picked up anaphorically: the sentence can meaningfully be followed by "He did it with gusto," in which the "it" anaphorically links to a hidden variable ranging over events.

It is far from clear that the analyses generated by semanticizing accounts pass this test. In order for them to do so, it would have to be possible to follow any scare-quoting sentence with another one picking up its hidden reference to some other speaker or to some (purely) quoted expression. And while in some cases it seems that this can be done (e.g. Krugman) in others it is far from clear. To see this, let's pair an explicit semanticization followed by a felicitous anaphoric uptake of the terms for expression and/or speaker, with the same-now far from felicitousattempted uptake on the original scare-quoting sentence:

\section{- Murderer}

Semanticized: Someone that some people called a "murderer" moved into a Harlem townhouse. They didn't say that to his face, however.

Original: A cross-dressing "murderer" moved into a Harlem townhouse. *They didn't say that to his face, however.

\section{- Militia}

Semanticized: Another fine day for what some have called America's "well regulated militia." They called it that because that phrase is in the Constitution.

Original: Another fine day for America's "well regulated militia." *They called it that because that phrase is in the Constitution.

\section{- Tardigrade}

Semanticized: The tardigrade... is particularly impressive among those items in the exhibit that some people called "extremeophiles." They applied that term to a small proportion of the items. 
Original: The tardigrade... is particularly impressive among the exhibit's "extremeophiles." *They applied that term to a small proportion of the items.

I should emphasize that I don't take this test to be decisive against all such accounts, since it's not clear whether each of them undertakes the same commitments as the Davidsonian claim about logical form. (Brandom's claim about what is "implicit" in a claim, for example, may very well not do so. On the other hand, the Geurts-Maier DRS approach does, it seems to me.)

Stepping back from their problems, however, on reflection these approaches seem much less well motivated by the core idea than they might appear at first. From the point of view of the incorporation approach, there is no more reason to semanticize the role of lexicon and context in cases of scare-quoting than there is to do so in the very simplest uses of speech. That is, there is no more to motivate these approaches to scare-quotation than there is to motivate an approach to all utterances on which, for example, an utterance by John of "Ann smokes" gets analyzed as "What John refers to as 'Ann' has the property that he expresses with 'smokes'." Presumably that approach to "Ann smokes" has no appeal whatsoever. But it seems no less applicable than the semanticizing approach to sentences involving scarequoting - so why should they seem any better motivated? In short: Why even try to semanticize the pre-semantic?

\subsection{Predelli}

I move on now to non-semanticizing accounts.

Stefano Predelli's 2003 account (which inspired me to do the style manual survey) applies to scare-quoting an idea proposed in applications to other matters both by Kent Bach (1999) and Stephen Neale (1999). But this particular application of the Bach-Neale idea founders, I will argue, on certain data concerning scare-quoting: most pointedly when there are context-sensitive expressions in the scare-quoted phrase.

The idea proposed by Bach and by Neale is that a sentence can express more than one proposition. Bach in particular argues that the cases usually cited as cases of conventional implicature are not cases of that, but are cases in which a sentence expresses more than one proposition. Some words or other devices trigger such multiple propositions. "So, for instance, according to a plausible development of Bach's view," Predelli writes, "the lexical entry for 'but' specifies as part of that expression's conventional behavior the fact that sentences of the form $P$ but $Q$ encode further information, besides the content that $P$ and $Q$ " (7). Predelli continues, elaborating his terminology as follows:

I refer to the content thus generated as the attachment associated with a sentence, as contrasted with its customary message; I call an expression responsible for the presence of an attachment, an attachment-trigger. (7) 
While the attachment-trigger makes it the case that some attachment is generated, contextual factors often determine which attachment is generated. (8)

Predelli's application of the multiple-propositions idea to scare-quoting is this. Scare-quotes are attachment triggers, so a sentence with a scare-quoted part expresses both a message content and an attachment content. The message content is "compositionally determined on the basis of the customary contributions provided by the expressions occurring in [the sentence], including those appearing within quotes" (13-14). That is, it's the message standardly expressed by the sentence with its scare-quotes stripped out. The attachment content, while triggered by the quotation marks, "must be contextually recovered" from the sentence as a whole and various background factors (14).

This sort of account is understandable as an attempt to capture all of what is going on in scare-quoting: both what is expressed and what is suggested. (It should be clear that my concern in this paper has been the former.) It has appealed to other writers as well: Manuel Garcia-Carpintero (2005: 102-04) endorses Predelli's account, and Cappelen and Lepore (2007: 16-17) find its approach congenial (although they differ from Predelli on how to categorize the attachment content).

As my focus is on what is semantically expressed by a sentence (in context), my discussion will concern Predelli's account of the message content. Predelli's account of this seems vulnerable to some pretty clear counterexamples.

Predelli does recognize that there are cases in which his account of how the message is determined seems to fail. When the scare-quoted aren't standard English, there is no "customary contribution" that they make to the meanings of English sentences. Predelli's account then entails that if there are such cases of scarequoting, then there is no message expressed by them. In his 2003 paper he seems to embrace this consequence:

the sentence

I am not a 'philtosopher'

does not in all likelihood express any message regarding my profession, since the nonword "philtosopher" fails to provide a compositional contribution. (24)

(García-Carpintero concurs, writing, "I think we should deal with [such] cases ... by accepting that the messages are the more or less absurd ones obtained according to the unembellished account" (2005: 104).) Predelli's line seems to be that scarequoting of items outside the speaker's lexicon can be "acceptable" (24) (despite not expressing message contents) only when used in what Laurence Horn (1985) has labelled "metalinguistic negation," as in

I am not a 'philtosopher', I am a philosopher.

But there are many cases of scare-quoting extra-lexical items that are entirely legitimate and are not metalinguistic negation. As we saw, some style manuals say that a major use of scare-quotes is precisely to flank expressions that are "foreign to the normal vocabulary of the speaker" (Chicago 1982). In many cases, then, the entire point of the scare-quoting is to express a proposition for which the speaker's 
own lexicon is inadequate. We should want truth conditions, not just suggested contents, for such cases.

In a subsequent paper Predelli modifies the account so that it does not have this objectionable consequence, or at least doesn't have it as straightforwardly. His modification exploits the fact that one of the interpreter's pre-semantic tasks is that of selecting lexical entries for the uttered words. And here there is some room for flexibility concerning mispronunciations and misspellings. So an interpreter can justifiably select the English lexical entry for "philosopher" when interpreting a sentence in which "philtosopher" occurs scare-quoted. By emphasizing the interpreter's leeway in choice of lexical items, Predelli can now say:

the content semantically derived once the appropriate lexical items have been selected is straightforwardly obtainable on the basis of the customary regularities governing the English language. (Predelli 2005: 163, my emphasis)

While this seems correct as far as it goes, I don't think that it's enough to make this a plausible treatment of the message expressed. There are two serious problems remaining.

One is that the "charitable representational attitude" (163) crucial to this account can only go so far. It will not go far enough to handle cases of scare-quoting in which (to work with English as an example) the non-English word is not justifiably construed as an attempted tokening of an item from the lexicon of English. (Many cases of scare-quoted slang will be like this, as will scare-quotings of words used with meanings other than the speaker's, as in Krugman.)

The deeper and more decisive problem though is that Predelli's solution addresses only one component of the interpretative task that scare-quoting imposes, that of choosing the lexical items for the scare-quoted words. The other dimension, that of choosing a context for their evaluation, is entirely unaddressed by Predelli's line. So his solution for scare-quotings of "philtosopher" and the like, even if it did work, doesn't carry over to a solution to scare-quotings of indexical expressions. In such cases simply stripping off the quotation marks results in a sentence with a clearly very different truth condition, no matter how much reasonable leeway one uses in assigning lexical items to the tokened words. ${ }^{12}$ Taking the Predelli approach to Denikin, for example, gives a sentence apparently about Professor Kotkin's troops:

After Denikin triumphantly entered Tsaritsyn and attended services in its Orthodox cathedral, on July 3, he ordered our armed forces to advance on Moscow.

\footnotetext{
${ }^{12}$ I believe that this problem also arises for the account offered by Gomez-Torrente, this volume, who writes that in what he calls "distance uses" of quotation marks-one subset of our data"the [quotation] marks work roughly as a parenthetical main clause paratactically added to the full sentence without quotes, and expressing the mentioned suggestion of the utterer's" (MS p. 26). Stripping out the scare-quotes does create problems if they flank indexicals, even in cases of distance use.
} 
(Similarly with Bush; there the first occurrence of "I" is scare-quoted, and stripping out the scare-quote marks starkly changes the truth condition.) $)^{13}$

One might wonder whether the problem Predelli's view has with counterexamples is just a question of detail. Is the message-and-attachment framework wholly refuted by there being problems with his implementation of it?

In the abstract, perhaps not. But the failure of Predelli's account of how the sentence determines a "message" content means that some other account is needed. And in this task the overarching framework of message and attachment is no help: we are back at the problem of finding out how the truth conditions of sentences are determined by the meanings of the component expressions and the manner in which those meanings combine. Since it is that question to which my proposal is addressed, there is, at least in the abstract, the possibility of combining that account (of scarequoting as incorporation), construed as an account of the "message" content that a scare-quoting sentence expresses, with an account of how the quotation marks trigger the generation of "attachment" contents.

Whether there would be any explanatory gain in such a framework is not a question I will pursue here. My aim here is just to argue that the treatment of scare-quoting as incorporation does succeed in getting the truth conditions of scarequoting sentences right, and that Predelli's account, while it proposes an interesting framework, does not succeed in that task.

\subsection{Shan}

Chung-chieh Shan (2010) gives a categorial grammar for a fragment of English with a mix of use and mention. (His account seems designed to handle the same range of cases I've put under the heading of "scare-quoting" plus those I've classified as mixed quotation).

His idea is that we conjoin two languages' syntax and semantics. Take English and [George W.] Bush-English as distinct languages, both deployed in

Bush is proud of his "eckullectic" reading list.

\footnotetext{
${ }^{13}$ Somewhat remarkably, in light of the forcefulness with which they press data involving mixed quotations of indexicals as refuting others' views, Cappelen and Lepore don't consider the very same phenomenon in scare quotations as posing a problem for their view that scare-quotes don't affect truth conditions:

the quotes in mixed quotations cannot be dropped [without change of semantic content] ... In scare-quoting they can be dropped without a loss of semantic content (at least according to every theory of scare-quoting in print that we know about). $(2007,17)$
}

To me it seems that the indexicals-based case against stripping out quotation marks from scare quotations is clearly just as strong as that against doing so from mixed quotations. 
The quote-marked part is interpreted by taking it (along with the marks) as a quotation expression, whose syntax is such that when its argument is of grammatical category $A$ in Bush-English, it itself is of category $A$ in English. (Unenclosed in quotation marks, the Bush-English expression is of type $A^{\prime}$ in English, which has no role in English except within quotation marks. This is necessary to prohibit "Bush is proud of his eckullectic reading list" being a sentence of English.) Its semantics is that the content of the quotation expression is the content of the quoted expression at a world/context, where the world and the context are somehow determined by conversational presuppositions or implicatures. (Shan cites Geurts and Maier (2005) as working with the former idea and Potts (2007) as working with the latter, but puts the matter to the side.) In this respect quotation is a rigidifier, as is Kaplan's "dthat" functor.

This proposal and mine have some ideas in common. One is that the content of the quotation expression is settled by what the quoted expressions are used to mean in a context (typically not that of the overall statement) that is somehow indicated to the interpreter. (Predelli's proposal, as we saw, fails to take change of context into account.)

As far as truth conditions go, it seems that Shan's proposal gives the same results as does the incorporation treatment. However, it involves some specialized apparatus introduced for the sole purpose of handling mixed- and scare-quotation. Shan even generalizes it to handle pure quotation, by introducing a novel conception of a context of utterance (439-40). Noting that formally we can think of contexts as functions from expression-world pairs to contents, Shan says that some contexts can return quotable items as the contents of expression-world pairs. Here again, while this works formally, it is definitely a huge departure from the Kaplanian conception of context. There is no such thing in Kaplan's conception as an "identity context" that, given an expression and a world, returns that expression.

Shan's proposal is ingenious and interesting in its own right. What mine highlights, however, is that such an apparatus isn't required to get the truth conditions right. All that is required is a joint deployment of treatments of intrasentential change of lexicon and context - and again, these are phenomena we must acknowledge for reasons having nothing to do with mixed- or scare-quotation. So while the Shan apparatus works, it's not needed to handle the phenomena. The tools for handling code-switching and for handling Two Heres and the like, when deployed together, suffice - and again, neither of those kinds of phenomena is in any way quotational.

The incorporation account of scare-quoting fares quite well in comparison with other accounts. In relation to semanticizing accounts, it has the virtue of relative simplicity, and fares better on the anaphoric-uptake test; in relation to Predelli's, it does a better job getting truth conditions right; and in relation to Shan's, it sticks more within the Kaplanian conception of context, and is simpler inasmuch as it doesn't require postulating any new syntactic or semantic rules for interpreting the quotation-mark-flanked expressions. 


\section{Incorporation and Assertion}

In this paper I've explained what incorporation is and argued that scare-quoting is best explained as a use of incorporation. Along the way we've seen some evidence of the utility of incorporation. As the survey showed, there are a variety of purposes for which writers (and speakers, using finger-quotes) scare-quote. Sometimes it's the poetic or rhetorical qualities that are worth capturing (e.g. Denikin); sometimes it's that one wants to remind one's readers that a phrase was used previously (e.g. Militia). But what I want to focus on in closing are cases in which one scare-quotes some phrase because one doesn't understand it well enough for it to be in one's own lexicon (e.g. Bugs, Chassis, Aiviq). For in these cases we see a very interesting consequence of our use of incorporation.

In these cases the effect of incorporation is that one asserts a content part of which one doesn't understand: a term that contributes some content to one's statement is not in one's lexicon. This certainly goes against one longstanding conception of assertion, on which it is the expression of (part of) the speaker's mental state-a judgement (Frege 1919: 294), a belief (Bach and Harnish 1979: 42), or a piece of the speaker's knowledge (Williamson 1996, 2000). I take it that for those mental states, there is no phenomenon analogous to scare-quoting: one cannot somehow incorporate into a belief or judgement, some content expressed by nothing in one's mental lexicon. So in these cases, I would argue, we have instances of the following schema: one asserts - sincerely, properly, competently — that $p$ while not believing, judging or knowing that $p$.

I note this only to highlight one implication of the claim that we engage in incorporation; a full discussion is for another occasion. Perhaps we have here some data that favor accounts of assertion on which it is not constitutively tied to the speaker's mental states. There are conceptions fitting that general description: conceptions on which assertion is a matter of updating shared conversational background (Stalnaker 1978; Lewis 1979), or changing normative status (Brandom 1983, 1994), or simply a conventional act made possible by certain linguistic "force indicators" (Segal 1990; Kolbel 2010). There are many connections to be explored between scare-quoting (and other borderline quotational phenomena) and central philosophical concepts such as that of assertion. ${ }^{14}$

\footnotetext{
${ }^{14} \mathrm{I}$ 'm grateful for audiences at presentations of these ideas at the 2015 Pacific Division APA conference (at a special session organized by Nellie Wieland), the 2015 Canadian Philosophical Association Congress, and The 1st Context, Cognition and Communication Conference at the University of Warsaw in June 2016, especially from Jonathan Wright following on the APA presentation; and to Stefano Predelli and Paul Saka for comments on a previous draft of this paper.
} 


\section{References}

Abbott, B. (2005). Some notes on quotation. Belgian Journal of Linguistics, 17, 13-26.

Almog, J., Perry, J., \& Wettstein, H. (Eds.). (1989). Themes from Kaplan. Oxford: Oxford University Press.

Bach, K. (1999). The myth of conventional implicature. Linguistics and Philosophy, 22, 327-366.

Bach, K., \& Harnish, R. M. (1979). Linguistic communication and speech acts. Cambridge, MA: MIT Press.

Baker, S. (1984). The complete stylist and handbook (3rd ed.). New York: Harper \& Row.

Benbaji, Y. (2004). A demonstrative analysis of "open quotation". Mind \& Language, 19, 534-547.

Birchfield, R. W. (2004). Fowler's modern English usage (3rd ed.). Clarendon Press. First edition edited by Henry Fowler.

Boyd, J. P., Cullen, C. T., Catanzariti, J., Oberg, B. B., et al. (Eds.). (1950). The papers of Thomas Jefferson. Princeton: Princeton University Press.

Brandom, R. (1983). Asserting. Nous, 17, 637-650.

Brandom, R. (1994). Making it explicit. Cambridge, MA: Harvard University Press.

Braun, D. (1996). Demonstratives and their linguistic meanings. Nous, 30, 145-173.

Cappelen, H., \& Lepore, E. (1997). Varieties of quotation. Mind, 106, 429-450.

Cappelen, H., \& Lepore, E. (2005). Varieties of quotation revisited. Belgian Journal of Linguistics, $17,51-75$.

Cappelen, H., \& Lepore, E. (2007). Language turned on itself: The semantics and pragmatics of metalinguistic discourse. Oxford: Oxford University Press.

Chicago. (1982). The Chicago manual of style (13th ed.). Chicago: University of Chicago Press.

Chicago. (2010). The Chicago manual of style (16th ed.). Chicago: University of Chicago Press.

Clark, H. H., \& Gerrig, R. (1990). Quotations as demonstrations. Language, 66, 764-805.

Cumming, S. (2005). Two accounts of indexicals in mixed quotation. Belgian Journal of Linguistics, 17, 77-88.

Davidson, D. (1963). Actions, reasons, and causes. Journal of Philosophy, 60, 685-700.

Davidson, D. (1979). Quotation. Theory and decision 11: 27-40. Reprinted in Inquiries Into Truth and Interpretation, 79-92. Oxford: Oxford University Press.

De Brabanter, P. (2005). Introduction. Belgian Journal of Linguistics, 17, 1-12.

De Brabanter, P. (2013). A pragmaticist feels the tug of semantics: Recanati's "Open quotation revisited". teorema, 32, 129-147.

Ehrlich, E., \& Murphy, D. (1991). The HarperCollins concise dictionary of English usage. New York: HarperCollins.

Fowler, H. W. (1926). A dictionary of modern english usage. Oxford: Oxford University Press.

Frege, G. (1919). The thought: A logical inquiry. Beiträge zur Philosophie des Deutschen Idealismus Translated by A. M. and Marcelle Quinton in Mind, 65, 289-311.

Garcia-Carpintero, M. (2005). Double-duty quotation: The deferred ostension account. Belgian Journal of Linguistics, 17, 89-108.

Georgi, G. (2015). Logic for languages containing referentially promiscuous expressions. Journal of Philosophical Logic, 44, 429-451.

Geurts, B., \& Maier, E. (2005). Quotation in context. Belgian Journal of Linguistics, 17, 109-128.

Gibaldi, J. (1998). MLA style manual and guide to scholarly publishing (2nd ed.). New York: The Modern Language Association of America.

Gomez-Torrente, M. (2017). Semantics vs pragmatics in impure quotation. In P. Saka \& M. Johnson (Eds.), The semantics and pragmatics of quotation (pp.135-167). Cham: Springer.

Greenbaum, S. (1996). The Oxford English grammar. Oxford: Oxford University Press.

Grunwald, M. (2012). The new new deal: The hidden story of change in the Obama Era. New York: Simon \& Schuster.

Horn, L. R. (1985). Metalinguistic negation and pragmatic ambiguity. Language, 61, 121-174. 
Johnson, M. (2017). Quotation through history: A historical case for the proper treatment of quotation. In P. Saka \& M. Johnson (Eds.), The semantics and pragmatics of quotation (pp.281302). Dordrecht: Springer.

Kaplan, D. (1977). Demonstratives. In Almog et al. (1989), 481-614.

Kaplan, D. (1989). Afterthoughts. In Almog et al. (1989), 567-614.

Keeley, B. (2010). The book of unnecessary quotation marks. San Francisco: Chronicle.

Kempson, R., Meyer-Viol, W., \& Gabbay, D. (2001). Dynamic syntax: The flow of language understanding. Oxford: Blackwell.

Kierzek, J. M. (1977). The Macmillan handbook of English (6th ed.). New York: Macmillan. Sixth edition revised by Robert F. Willson, Jr.

Kolbel, M. (2010). Literal force: A defence of conventional assertion. In S. Sawyer (Ed.), New waves in philosophy of language (pp. 108-137). London: Palgrave Macmillan.

Kotkin, S. (2014). Stalin: Volume I: Paradoxes of Power, 1878-1928. Penguin.

Lewis, D. (1979). Attitudes de dicto and de se. Philosophical Review, 88, 513-543. Reprinted in 'Philosophical Papers' (1983), (pp.133-159). Oxford: Oxford University Press.

Maier, E. (2015). Quotation and unquotation in free indirect discourse. Mind \& Language, 30, 345-373.

McCarten, J. (2013). The Canadian press stylebook (17th ed.). Canadian Press.

Neale, S. (1999). Coloring and composition. In K. Murasugi \& R. Stainton (Eds.), Philosophy and linguistics (pp. 35-82). Boulder: Westview.

Perrin, P. G., \& Smith, G. H. (1968). Handbook of current English (3rd ed.). Atlanta: Scott, Foresman and Company. Third edition revised by Jim W. Corder.

Poplack, S. (1980). Sometimes I'll start a sentence in Spanish Y TERMINO EN ESPAN $\sim$ OL: Toward a typology of code-switching. Linguistics, 18, 581-618.

Poplack, S., \& Sankoff, D. (1984). Borrowing: The synchrony of integration. Linguistics, 22, 99 136.

Potts, C. (2007). The dimensions of quotation. In C. Barker \& P. Jacobson (Eds.), Direct compositionality (pp. 405-431). Oxford: Oxford University Press.

Predelli, S. (2003). Scare quotes and their relation to other semantic issues. Linguistics and Philosophy, 26, 1-28.

Predelli, S. (2005). 'Subliminable' messages, scare quotes, and the use hypothesis. Belgian Journal of Linguistics, 17, 153-166.

Purver, M., \& Kempson, R. (2004). Incrementality, alignment and shared utterances. In J. Ginzburg \& E. Vallduv1 (Eds.), Catalog '04: Proceedings of the eighth workshop on the semantics and pragmatics of dialogue (pp. 85-92). Barcelona: Department of Translation and Philology, Universitat Pompeu Fabra, Barcelona.

Recanati, F. (2000). Oratio Obliqua, Oratio Recta: An essay on metarepresentation. Cambridge, MA: MIT Press.

Recanati, F. (2001). Open quotation. Mind, 110, 637-687.

Recanati, F. (2010). Truth-conditional pragmatics. Oxford: Clarendon Press.

Saka, P. (1998). Quotation and the use-mention distinction. Mind, 107, 113-135.

Saka, P. (2013). Quotation. Philosophy Compass, 8, 935-949.

Segal, G. (1990). In the mood for a semantic theory. Proceedings of the Aristotelian Society, 91, $103-118$.

Shan, C.-c. (2010). The character of quotation. Linguistics and Philosophy, 33, 417-443.

Stalnaker, R. (1978). Assertion. Syntax and Semantics, 9, 315-322. Reprinted in 'Context and content' (1999), (pp. 78-95). Oxford: Oxford University Press.

Stanley, J., \& Williamson, T. (1995). Quantifiers and context-dependence. Analysis, 55, 291-295.

Stilman, A. (2010). Grammatically correct: The essential guide to spelling, style, usage, grammar, and punctuation. Cincinnati: Writer's Digest Books.

Swan, M. (2005). Practical English usage (3rd ed.). Oxford Uinversity Press.

Todd, L., \& Hancock, I. (1986). International English usage. London: Routledge.

Williamson, T. (1996). Knowing and asserting. Philosophical Review, 105, 489-523.

Williamson, T. (2000). Knowledge and its limits. Oxford: Oxford University Press. 